\title{
Oceans of Data: OcEanographic CD-ROMS FOR RESEARCH AND EDUCATION
}

\author{
By Elizabeth Smith
}

\begin{abstract}
Compact disc-Read Only Memory (CDROM) technology has been used for a scant 7 years in oceanography, mainly for the distribution of data by the national archives of the National Oceanic and Atmospheric Administration (NOAA) and National Aeronautics and Space Administration (NASA). In the early days of CD-ROM, skepticism was prevalent. CD-ROMs were too flashy for "real" oceanographers. CDROM drives were expensive and there were very few collections of data published on CD-ROM to warrant the expense. It was a nice experiment but that was all. Today, a myriad of factors including low cost, convenience, efficiency, longevity, and the huge volumes of data available all have helped prove CD-ROM's utility as an archive, distribution, exchange and backup medium for oceanographic data. In this article, I will discuss the brief evolution of CD-ROM technology and provide a list of resources for ocean data and information available on CD-ROM.
\end{abstract}

\section{The Evolution of CD-ROM}

CD-ROM is based on the highly successful CD audio technology developed by Philips and Sony in the early 1980s. Almost everyone has a music CD player at home and all audio CDs can be played in all manufacturers players. But it wasn't until 1988 that CD-ROM manufacturing was standardized in the same way as audio CD manufacturing. ISO 9660 is the name given to the standard logical format for recording directories and data files on CD-ROM, resulting in complete platform portability. Software provided with data-packed CD-ROMs is generally developed for specific plat-

E. Smith, Center for Coastal Physical Oceanography, Old Dominion University, Norfolk, VA 23529 , USA. forms and applications. Macintosh and IBM PC (or clone) software (e.g., image display or data plotting) is usually provided. The advent of standard data formats like Hierarchical Data Format (HDF) and Common Data Format (CDF or NetCDF) has led to the development of CD-ROMs that can be used (both software and data) on UNIX systems as well as personal computers. Therefore, a key question one must ask when purchasing a data collection on CD-ROM concerns the software provided to manipulate the data.

I bought my first CD-ROM drive in 1988 for $\$ 1,000$. The only drive I could buy then, for a Macintosh, was an Apple CD-ROM drive. Today the fastest CDROM drives cost as little as $\$ 250$, and third-party vendors compete for Macintosh, IBM PC, and UNIX-based computer markets. "Multi-media" computers generally come with a built-in CD-ROM drive as part of the package. The cost of CD-ROM titles in oceanography is rarely more than $\$ 100$, although commercially produced CD-ROM sets of satellite images, to give one popular example, can cost upwards of \$200. CDROM subscriptions to abstract collections, which are updated quarterly, are an order of magnitude more expensive and are almost always available at a university library. Many CD-ROM titles for use in oceanographic research and education, such as all of those available from the JPL Physical Oceanography Distributed Active Archive Center (PO.DAAC), are free of charge. More and more data collections are being distributed solely on CD-ROM. In 1990, NOAA's National Oceanographic Data Center (NODC) launched a project to make virtually all of its data available on CDROM. Because of its convenience, the demand for data on CD-ROM is steadily growing. Susan Digby, Head of User Ser- vices at the JPL PO.DAAC, reports that some users will not order data unless it is available on CD-ROM.

Early on, use of CD-ROM for data distribution was deemed appropriate only for large, static data sets. Since CD-ROMs were expensive and complicated to produce, data published on CD-ROM were chosen very carefully. Until recently, CDROMs had to be manufactured by vendors with expensive and specialized equipment. Data were provided to a vendor on magnetic tape and a pre-mastering process was required to add the needed logical structure of the disk. One of the first NASAsponsored oceanographic CD-ROM production projects, the West Coast Time Series Coastal Zone Color Scanner CDROM, cost the agency approximately $\$ 80$ per CD-ROM including mastering costs. Today, the pre-mastering and mastering cost is about $\$ 1,000$ per title and the cost per replica has plummeted to under $\$ 2.00$. The pre-mastering and mastering process is no longer exclusively the realm of thirdparty vendors, which is driving costs down even further. CD-ROM recorders, which include mastering software for PCs and Macintoshs, cost around $\$ 3,000$, making CD-ROM a medium for much more than the distribution of large, static data sets. NODC can provide to its customers data selected from its archive data files on so-called "one-off" CD-ROMs, using its own CD-ROM recorder and a PC. The National Snow and Ice Data Center provides investigators with a subscription of Special Sensor Microwave Imager polar data on CD-ROMs on a continuing basis, free of charge. UNIX mastering software costs are not so reasonable, unfortunately, although the CD-ROM recorder itself is the same for any platform. Expect to pay in the neighborhood of $\$ 10,000$ for mastering software for a UNIX platform. 


\section{Classroom Compatibility}

Because CD-ROMs can store about 700 megabytes of information, and because of the wide-spread use of CDROM readers on personal computers, CD-ROM data collections are very well suited for teaching. Magnetic disk and tape drives for data storage are more difficult to use, more expensive and less prevalent in the classroom than CD-ROM drives. Some oceanographic CD-ROM titles are ideal for use in the undergraduate or graduate classroom, either for demonstration purposes or for hands-on exercises. The following are two CD-ROMs I can personally recommend for educational use:

- A CD-ROM Atlas of Data from the Chesapeake Bay Monitoring Program produced by the Virginia Institute of Marine Science (Rennie and Neilson, 1994) and available free of charge. [Contact rennie@vims.edu.]

- Monthly Mean Distributions of Satellite-Derived Sea Surface Temperature and Pigment Concentration (5 disc set) produced by the NASA/JPL PO.DAAC (Tran et al.. 1993) and available free of charge. [Contact podaac@podaac.jpl.nasa.gov.]

Both of these CD-ROMs were used in a small (9 students) Biological Oceanography laboratory class at Old Dominion University, in which we had access to four Macintosh computers with CD-ROM drives. The students worked in pairs or threes and each group had its own workstation. The data on both the JPL PO.DAAC and VIMS CD-ROMs are monthly averaged images of various parameters and are ideally suited for handson exploration. Coincidentally, both of these CD-ROMs make use of image display software, from the National Center for Supercomputing Applications (NCSA), which is easy to learn and intuitive to use. The time allotted for each lab was about 4 hours which was scarcely long enough for a brief introduction to the data (this took longer in the case of the satellite data CD-ROMs), demonstration of the CD-ROM software in a lecture style, and hands-on work by the student pairs. An exercise completed by the students was to record the sea surface temperature and pigment data at two lo- cations for 12 months and write a description of what they saw in the time-series. These data were collected from the CD-ROMs using the NCSA software provided and examined as time-series. This exercise afforded experience in several arenas: working with large CD-ROM data sets, familiarization with satellite-derived data, simple image manipulation, and analysis of time-series.

Obviously, CD-ROMs containing primarily images are also useful for research. The JPL PO.DAAC temperature and pigment $\mathrm{CD}-\mathrm{ROM}$ s contain the data in image form, but the images can easily be converted to geophysical units. The VIMS CDROM contains the images as well as all of the raw, station data used to create the images. On the other hand, many CD-ROM titles are suited for research purposes only, and require a significant investment of time and computer resources in order to be readily used in the classroom. One such data set is the formidable collection of TOPEX/POSEIDON Altimeter Merged Geophysical Data Records, which contains no image data, and is specifically described as being "research data", with analysis and display software being the responsibility of the user.

Table 1

World Wide Web servers which contain detailed information about oceanographic CD-ROMs and CD-ROM resources

\begin{tabular}{|c|c|c|c|}
\hline Agency & WWW Location & Phone & E-mail \\
\hline NOAA & http://www.noaa.gov & & \\
\hline $\begin{array}{c}\text { National Oceanographic } \\
\text { Data Center (NODC) }\end{array}$ & http://www nodc.noaa.gov & $(202) 606-4549$ & services@nodc.noaa.gov \\
\hline $\begin{array}{l}\text { National Climatic Data } \\
\text { Center (NCDC) }\end{array}$ & http://www.ncde.noaa.gov & (704) $271-4800$ & orders@ncdc.noaa.gov \\
\hline $\begin{array}{l}\text { National Geophysical } \\
\text { Data Center (NGDC)-- } \\
\text { Marine Geophysics }\end{array}$ & http://www.ngdc.noaa.gov & (303) 497-6144 & ganderson@ngdc.noaa.gov \\
\hline $\begin{array}{l}\text { NASA Distributed Active } \\
\text { Archive Centers }\end{array}$ & http:/hypatia.gsfc.nasa.gov/NASA_homepage.html & & \\
\hline $\begin{array}{l}\text { Alaska SAR Facility } \\
\text { (polar processes; SAR) }\end{array}$ & http://eosims.asf.alaska.edu:12355/asf_homepage.html & (907) 474-6166 & asf@eos.nasa.gov or uso@eosims.asf.akaska.edu \\
\hline $\begin{array}{l}\text { Goddard Space Flight } \\
\text { Center (atmospheric } \\
\text { dynamics \& global } \\
\text { biosphere) }\end{array}$ & http://daac.gsfc.nasa.gov & (301) $286-3209$ & gsfc@eos.nasa.gov or daacuso@eosdata.gsfc.nasa.gov \\
\hline $\begin{array}{l}\text { Jet Propulsion Laboratory } \\
\text { (physical oceanography) }\end{array}$ & http://podaac-www.jpl,nasa.gov & (818) 354-9890 & jpl@eos.nasa.gov or podaac@podaac.jpl.nasa.gov \\
\hline $\begin{array}{l}\text { Langley Research Center } \\
\text { (radiation, clouds, } \\
\text { aerosols, tropospheric } \\
\text { chemistry) }\end{array}$ & http://eosdis.lare.nasa.gov & (804) 864-8656 & larc@eos.nasa.gov or userserc@eosdis.larc.nasa.gov \\
\hline $\begin{array}{l}\text { National Snow \& Ice Data } \\
\text { Center (snow \& ice, } \\
\text { cryosphere \& climate) }\end{array}$ & http://eosims.colorado.edu: 1733 & (303) $492-6199$ & nsidc@eos.nasa.gov or nsidc@kryos.colorado.edu \\
\hline $\begin{array}{l}\text { JPL Data Distribution } \\
\text { Laboratory Catalog of } \\
\text { Government Scientific } \\
\text { CD-ROMs }\end{array}$ & http://stargate.jpl.nasa.gov: 1080 & $(818) 306-6130$ & pds_operator@jplpds.jpl.nasa.gov \\
\hline
\end{tabular}

Many of the titles listed in this table are available at a nominal fee or are free of charge. 


\begin{tabular}{|c|c|c|}
\hline Title & From & Phone \\
\hline AQUALINE & AQUALINE & (UK) 079351171 \\
\hline Aquatic Sciences \& Fisheries Abstracts (AFSA) & Cambridge Scientific Abstracts & (301) $961-6741$ \\
\hline Arctic Data Interactive & Internetwork, Inc. & (619) $755-0439$ \\
\hline Carbonate Chemistry of the North Pacific \& Weddell Sea & Carbon Dioxide Info. Analysis Center & (615) 574.0390 \\
\hline Environment Abstracts on CD-ROM & Reed Reference Publishing & (800) $521-8110$ \\
\hline $\begin{array}{l}\text { Experiment on Rapidly Intensifying Cyclones over the Atlantic (ERICA) } \\
\text { Field Study }\end{array}$ & Drexel University & (215) $895-2786$ \\
\hline Fishing \& Fisheries Worldwide & National Information Services Corp. & (410) 243-0797 \\
\hline Genesis of Atlantic Lows Experiment (GALE) & Drexel University & (215) $895-2786$ \\
\hline GEOSECS Atlantic, Pacific, Indian and Mediterranean Radiocarbon Data & Carbon Dioxide Info. Analysis Center & $(615) 574-0390$ \\
\hline Introduction to Remote Sensing & Joint Education Initiative & (301) 405-2324 \\
\hline Marine Data Sampler & MRJ, Inc. & (703) $385-0746$ \\
\hline National Center for Supercomputing Applications & NCSA & (217) $244-0072$ \\
\hline North American Observational Data for July-December 1987 & University of Washington, Dept of Atmospheric Sciences & (206) 685-0910 \\
\hline Ocean in Motion & Wayzata Technology & (218) 326-0597 \\
\hline Ocean Life Vols. $1-3$ & Sumeria, Inc. & (415) $904-0800$ \\
\hline Oceanographic \& Marine Resources Vols. 1-2 & National Information Services Coro. & (410) $243-0797$ \\
\hline Radar Remote Sensing Imagery of Coastal Regions & AERDE Environmental Research & (902) $423-2211$ \\
\hline Small Blue Planet: The Electronic Satellite Atlas & Now What Software & (415) $885-1689$ \\
\hline $\begin{array}{l}\text { Surface-water \& atmospheric CO \& NO obs. by shipboard automated gas } \\
\text { chromatography: ' } 77-90\end{array}$ & Carbon Dioxide Info. Analysis Center & $(615) 574-0390$ \\
\hline The Theory of Plate Tectonics & TASA Graphic Arts Inc. & (505) $281-9090$ \\
\hline Water Resources Abstracts (updated quarterly) & SilverPlatter Information Inc. & (617) $769-2599$ \\
\hline World Climate Disc & Chadwyck-Healey Inc. & (703) $683-4890$ \\
\hline World WeatherDisc, Climate Data for Planet Earth & WeatherDisc Associates Inc. & (206) $524-4314$ \\
\hline
\end{tabular}

Many of these CD-ROMs are not free and some are quite expensive, especially the abstract and publications subscriptions like AFSA.

A new CD-ROM, called Exploring the Deep, contains software implemented as a teaching tool for large, introductory oceanography or geology classes. It was developed by Dr. William Prothero, Department of Geological Sciences, University of California, Santa Barbara, who reports that preliminary feedback from students who have used Exploring the Deep software is very positive. Teaching assistant workloads are reportedly diminished because of a computer homework grading module. Use of this software requires Macintosh computers, and software updates will be available via FTP. [Contact the UCSB Bookstore, P.O. Box 13400, Santa Barbara, CA 93107, (805)893-2367.]

Finally, I am aware of at least one col- lection of data on CD-ROM that has been published in the open literature. Cutter et al. (1994) is a collection of data on CDROM pertaining to a study described in Diaz et al. (1994). The CD-ROM is an appendix to the journal, Deep Sea Research II, which is a special issue devoted to a study of the continental slope off Cape Hatteras, NC. The full citations are at the end of this article.

\section{Oceans of Data}

By far the most prolific producer of oceanographic data on CD-ROM is NOAA. Most of NODC's vast data archives are distributed on mass-replicated CD-ROMs. Eleven different CD-ROM titles comprising over 50 separate discs are currently available. A recent NODC re- lease is the World Ocean Atlas 1994, a set of nine CD-ROMs of objectively analyzed global fields of temperature, salinity, oxygen, and nutrients at standard depth levels, plus the ocean profile data sets from which they were derived. Most NODC CDROMs cost under $\$ 80.00$ per disc. A custom selection of data on a "one-off" CDROM costs around $\$ 200$. The National Climatic Data Center and the National Geophysical Data Center also offer dozens of CD-ROM titles of potential interest to oceanographers, both researchers and educators. The consortium of cooperating data centers which makes up NASA's Earth Observing System Data and Information System, called Distributed Active Archive Centers (DAACs), offer dozens of kinds of ocean-related data on CD-ROM. The

Table 3

Catalogs of data and information on CD-ROM

\begin{tabular}{lcc}
\hline \multicolumn{1}{c}{ Catalog and Producer } & WWW Location \\
\hline Catalog of Government Scientific CD-ROM Titles & http://stargate.jpl.nasa.gov:1080/toc.html \\
Data Distribution Library & & Phone \\
Jet Propulsion Laboratory & none & $306-6303$ \\
CD-ROM Sourcebook for the Atmospheric, Oceanic, Earth and Space Sciences & & (603) 471-1802 \\
MeteoQUEST, Inc. &
\end{tabular}

These two catalogs list many scientific CD-ROM titles, including oceanographic data collections, and sources (but no pricing information). 
best way to learn about these CD-ROM titles is to take a look at the World Wide Web servers for these sites using Netscape or Mosaic. The specific WWW locations are given in Table 1, along with E-mail addresses and phone numbers.

Approximately 30 more ocean-related CD-ROMs from universities and private companies are listed in Table 2 , with phone numbers. Table 3 lists two catalogs of data and information published on CD-ROM in a variety of disci- plines including oceanography. Please notify me of any omissions, and I will post an updated list on the Oceanography Society bulletin board on WWW (http://www.tos.org). My e-mail address is lizsmith@ccpo.odu.edu.

\section{References}

Cutter, G.R., Jr., R.J. Diaz and J.A. Blake, 1994: Input, accumulation and cycling of materials on the continental slope off Cape Hatteras: CD-ROM Appendix. Deep-Sea Res. II, 41.

Diaz, R.J., J.A. Blake and G.R. Cutter, Jr., 1994:
Input, accumulation and cycling of materials on the continental slope off Cape Hatteras: An introduction. Deep-Sea Res. II, 4I, 705-982.

Rennie, S.E. and B. Neilson, 1994: A CD-ROM atlas of data from the Chesapeake Bay Monitoring Program. Virginia Institute of Marine Science Data Report No. 55, $13 \mathrm{pp}$.

Tran, A.V., E.A. Smith, J. Hyon, R. Evans, O. Brown and G. Feldman, 1992: Satellite-derived multichannel sea surface temperature and phytoplankton pigment concentration data: A CD-ROM set containing monthly mean distributions for the global oceans. JPL Publication D-10351, 31 pp. 